\title{
On The Strain Sensing of EVA/MWCNT Composite
}

\author{
RAZVAN TUDOR ROSCULET*, FELICIA STAN, CATALIN FETECAU \\ Dunarea de J os University of Galati, Center of Excellence Polymer Processing, 47 Domneasca, 800 008, Galati, România
}

\begin{abstract}
In this paper, the potential of using ethylene-vinyl acetate (EVA) filled with multi-wall carbon nanotubes (MWCNT) composites for strain sensing was investigated. Stress relaxation experiments were conducted on injection-molded samples, and the stress and electrical resistance were measured in situ during the relaxation process. Based on the experimental results, it was found that the electrical resistance of the EVA/ MWCNT composite increases with increasing strain, and exponentially decreases with relaxation time, indicating the capacitive behavior of MWCNTs. The maximum electrical conductivity of $7.35 \times 10^{-4} \mathrm{~S} / \mathrm{cm}$ was obtained for the EVA/MWCNT composite with 5 wt. $\%$ at $180^{\circ} \mathrm{C}$, whereas higher piezo-resistive sensitivity was obtained for the composite with $3 \mathrm{wt} \%$. The electrical percolation threshold was found to increase from 0.223 wt. $\%$ at $140^{\circ} \mathrm{C}$ to 0.994 wt. $\%$ at $180^{\circ} \mathrm{C}$.
\end{abstract}

Keywords: strain sensing, conductivity, stress relaxation, carbon nanotubes, polymer

In the last years, the production of composites was constantly increasing and the share of these materials used in civil and industrial [1], energy [2] or medical applications $[3,4]$ was also increasing. This tendency is supported by the physical and chemical properties of these materials, especially those of polymer-based composites $[5,6]$.

A special class of polymer-based composites is represented by carbon nanotubes (CNTs) reinforced polymers, which are characterized by enhanced mechanical, thermal and electrical properties [7, 8]. Polymer/CNT composites can exhibit the entire range of electrical properties, from electrical insulators to electrical conductors $\left(10^{2} \div 10^{-14} \mathrm{~S} / \mathrm{cm}\right)$ by tuning the CNT loading and processing conditions [9-11]. Moreover, the polymer/ CNT composites are electrically sensitive when subjected to external stress or strain [11-13].

Generally, piezoresistivity is the property of a material to modify its electrical resistivity as a result of the change in the stress or strain state, and is quantified by using the gauge factor, i.e. the relative change in electrical resistance as a function of the applied strain [14-19]. This property has inspired researchers to use polymer/CNT composites for monitoring the deformation and damage of structural components $[20,21]$. For example, to prevent the destruction of objects handled by industrial robots, one typical application of polymer/CNT composites is the fabrication of manipulators sensitive to grip force [22].

In general, the piezoresistive response of polymer/CNT composites was investigated under different cyclic loading [23-26]. However, the time-dependent electrical behavior of polymer/CNT composites was barely investigated. This is an important aspect owing to time-dependent behavior of polymer/CNT composites. Thus, the aim of this research is to investigate the time-dependent mechanical and electrical properties of ethylene-vinyl acetate (EVA) filled with multi-wall carbon nanotubes (MWCNT) composites manufactured by injection molding. Strain-controlled uniaxial relaxation testes were carried out at room temperature under various testing conditions, and the stress and electrical resistance were measured in situ during the relaxation process.

\section{Experimental part}

Material and sample preparation

The EVA/MWCNT composites with 1, 3 and 5 wt.\% of MW CNTs used in this study were supplied by Nanocyl S.A. (Belgium) in the form of pellets. According to the manufacturer, the EVA/MWCNT composites were prepared by melt mixing EVA with 20 wt.\% of vinyl acetate with Nanocyl NC $7000^{\mathrm{TM}}$ thin-multi walled carbon nanotubes.

The EVA/MWCNT tensile samples (fig. 1) were fabricated by injection molding according to ISO 527 Standard. To investigate the effect of injection molding temperature on the electrical properties, two injection molding temperatures were considered, 140 and $180^{\circ} \mathrm{C}$, which are the limits of the injection molding temperature range for EVA.

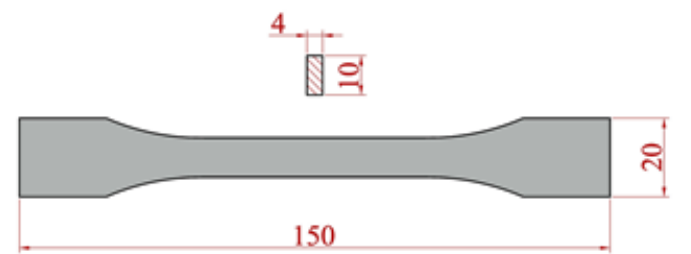

Fig. 1. Geometry of the injection-molded sample (Units in $\mathrm{mm}$ )

Stress relaxation and electrical sensitivity measurement

Figure 2 shows the experimental set-up used for investigating the effect of applied strain on electrical and mechanical properties of EVA/MWCNT composites, i.e. stress and electrical resistance relaxations. The DC conductivity of the composites was measured by a twoprobe method under strain-controlled procedure, as shown in figure 2. The measurements were performed on a Testometric universal testing machine (Model M350-5AT, UK) coupled with the Keisight direct current source (Model B2961B, USA) (fig. 3). The injection-molded samples were clamped in the grips, creating a gauge length of $115 \mathrm{~mm}$, while copper electrodes were fixed directly on the samples, creating a gauge length of $30 \mathrm{~mm}$, as shown in FIGUR E2. The surfaces in contact with the electrodes were covered with graphite paint for conductive coatings (GRAPHIT 33, Kontakt Chemie, Belgium). 


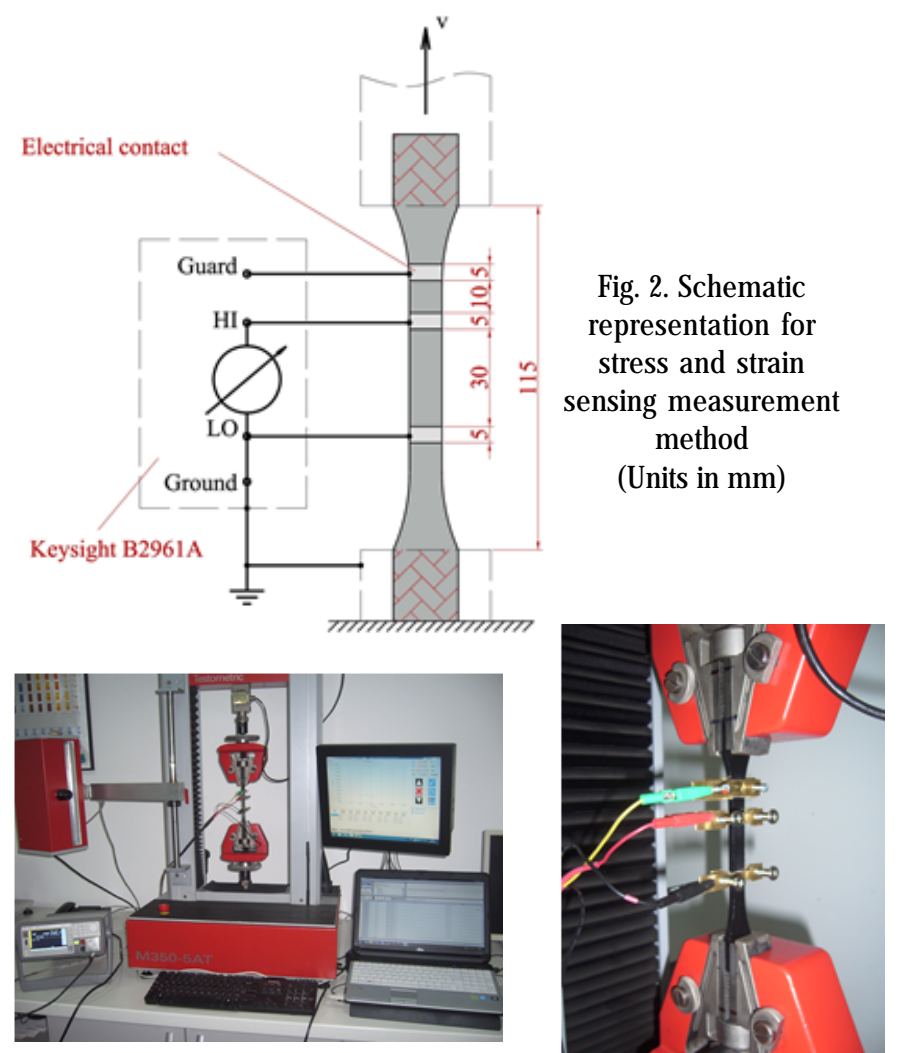

Fig. 3. Experimental set-up for stress relaxation and electrical resistance measurement

In the strain-controlled tests, i.e. linear ramp to a prescribed strain, the specimens were stretched to $0.5,1$, 2 , and $5 \%$ strain, respectively, with the strain rate of $5 \mathrm{~mm} /$ min. Following the ramp loading to the pre-defined strain level, the crosshead was stopped and the specimen was held constant over a prescribed time while the stress and electrical resistance were continuously recorded. The applied voltage was $40 \mathrm{~V}$, which generated currents between $2 \times 10^{-9}$ and $2 \times 10^{-2} \mathrm{~A}$, depending of the nanotube loading. In order to investigate the strain sensing reproducibility, three samples were tested for each set of process parameters, and the average and standard deviation reported.

\section{Results and discussions \\ Stress relaxation curves}

Figure 4 presents the tensile stress-strain curves at 5 $\mathrm{mm} / \mathrm{min}$. The stress-strain curves indicate that the tensile strength of EVA/MW CNT composite increases with increasing MWCNT wt.\%, while the strain at break decreases with increasing MWCNT wt.\%. As shown in figure 4, all samples are in linear visco-elastic (LVE) domain for strains up to $5 \%$.

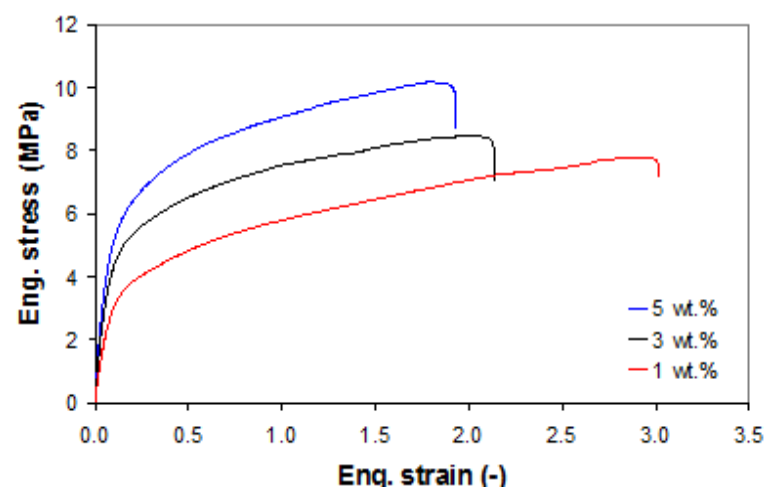

Fig. 4. Representative tensile stress-strain curves of EVA/MWCNT composites
Figure 5 presents the representative stress relaxation curves for EVA/MW CNT composite for a strain level of 0.5, 1,2 and $5 \%$, respectively, at a constant strain rate of 5 $\mathrm{mm} / \mathrm{min}$ and melt temperature of $180^{\circ} \mathrm{C}$. The relaxation stress was calculated under the assumption that, during the relaxation test, there is no change in the cross-section area of the specimens. Itshould be noted that the relaxation time was determined such that, for each initial strain, the ramp loading can be considered an ideal ramp (the relaxation time is at least ten times higher than the ramp loading) so the effect of ramp history can be neglected [27].

As shown in figure 5 , the stress dropped quickly at first and then slowed down approaching the equilibrium. For the same initial strain level, the corresponding initial relaxation stress, $\sigma_{\text {, increased due to the presence of }}$ carbon nanotubes, the higher the nanotube wt.\% is, the higher the initial stress, as can be seen in table 1 . At a given initial strain $\left(\varepsilon_{0}=5 \%\right.$, for example), the initial relaxation stress increases from 2.1 MPa to $3.622 \mathrm{MPa}$ (about $74 \%$ ) with increasing nanotube loading from 1 to $5 \mathrm{wt} . \%$. This indicates that the external loads are transferred to the nanotubes in terms of shear stress through the carbon nanotubes - EVA interface. On the other hand, as shown in table 1 , the recovery rate is about $80-90 \%$, the higher the nanotube loading is, the lower is the recovery rate.
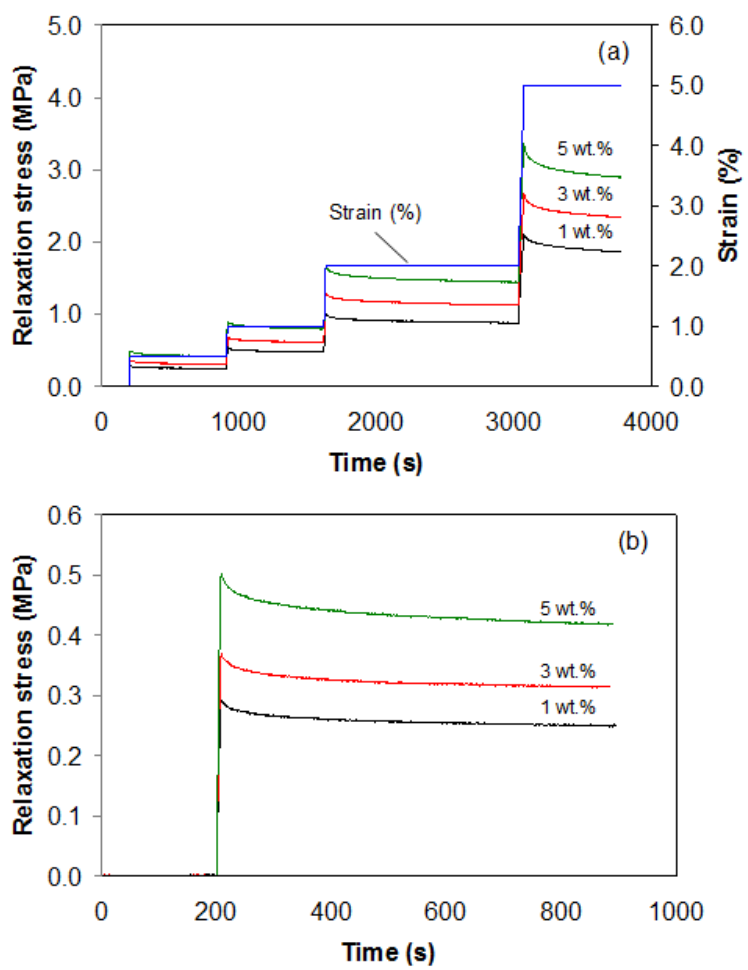

Fig. 5. Variation of stress relaxation as a function of time for EVA/ MWCNT composites (a) and detail for stress relaxation at $0.5 \%$ strain (b)

It should be noted that, in the low strain range, the effect of injection molding temperature on the stress relaxation behavior of EVA/MWCNT composites is not statistically significant. At higher strains (5 wt.\%), the relaxation stress slightly decreases with increasing melt temperature, especially at higher nanotube loading, as shown in table 1.

\section{Electrical properties of EVA/MWCNT composites}

First, the electrical resistance was measured under no loading conditions to evaluate the initial resistivity of the EVA/MWCNT composites. Figure 6 shows the electrical conductivity of unstrained EVA/MWCNT composite as a function of nanotube loading for two injection molding temperatures $\left(140^{\circ} \mathrm{C}\right.$ and $\left.180^{\circ} \mathrm{C}\right)$. 
Table 1

PARAMETERS FOR STRESS RELAXATION-STRAIN CONTROLLED TEST

\begin{tabular}{|c|c|c|c|c|c|c|}
\hline $\begin{array}{c}\text { Melt } \\
\text { temperature } \\
\left({ }^{\circ} \mathrm{C}\right)\end{array}$ & $\begin{array}{l}\text { Initial } \\
\text { strain } \\
(\%)\end{array}$ & $\begin{array}{l}\text { MWCNTs } \\
\text { (wt. \%) }\end{array}$ & $\begin{array}{c}\text { Initial stress } \\
\sigma_{0}(\mathrm{MPa})\end{array}$ & $\begin{array}{c}\text { Equilibrium } \\
\text { stress } \\
\sigma_{\infty}(\mathrm{MPa})\end{array}$ & $\begin{array}{c}\text { Recovery rate } \\
\sigma_{\infty} / \sigma_{0}\end{array}$ & $\begin{array}{l}\text { Relaxation ratio } \\
\left(\sigma_{0}-\sigma_{\infty}\right) / \sigma_{0}\end{array}$ \\
\hline \multirow{6}{*}{140} & \multirow{3}{*}{0.5} & 1 & 0.293 & 0.246 & 0.840 & 0.160 \\
\hline & & 3 & 0.378 & 0.321 & 0.849 & 0.151 \\
\hline & & 5 & 0.544 & 0.451 & 0.829 & 0.171 \\
\hline & \multirow{3}{*}{5} & 1 & 2.086 & 1.848 & 0.886 & 0.114 \\
\hline & & 3 & 2.728 & 2.369 & 0.868 & 0.132 \\
\hline & & 5 & 3.622 & 3.109 & 0.858 & 0.142 \\
\hline \multirow{6}{*}{180} & \multirow{3}{*}{0.5} & 1 & 0.284 & 0.242 & 0.852 & 0.148 \\
\hline & & 3 & 0.365 & 0.309 & 0.847 & 0.152 \\
\hline & & 5 & 0.488 & 0.404 & 0.828 & 0.173 \\
\hline & \multirow{3}{*}{5} & 1 & 2.105 & 1.875 & 0.891 & 0.110 \\
\hline & & 3 & 2.659 & 2.335 & 0.878 & 0.122 \\
\hline & & 5 & 3.311 & 2.857 & 0.863 & 0.137 \\
\hline
\end{tabular}

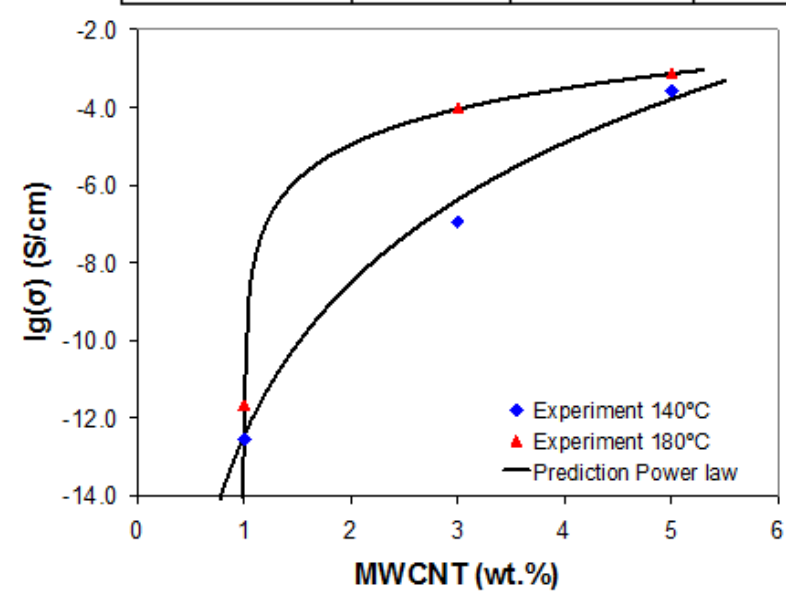

Fig. 6. Electrical conductivity of unstrained EVA/MWCNT composite

It was found that the conductivity of EVA/MWCNT composite increases with increasing nanotube loading and melt temperature. Although a small number of conductive paths are formed, the EVA/MW CNT composite with $1 \mathrm{wt} . \%$ behaves mostly like an insulator $\left(\sim 10^{-12} \mathrm{~S} / \mathrm{cm}\right)$. The sharp increase in the conductivity at 3 wt. $\%\left(\sim 10^{-5} \mathrm{~S} / \mathrm{cm}\right)$ indicates the formation of the conductive network. The maximum conductivity of $7.35 \times 10^{-4} \mathrm{~S} / \mathrm{cm}$ was obtained for EVA/MW CNT with 5 wt. $\%$ at $180^{\circ} \mathrm{C}$.

The experimental data in figure 6 were fitted to the power law model [28]:

$$
\sigma_{\mathrm{DC}}=\sigma_{\mathrm{DC}}^{0}\left(\phi-\phi_{c}\right)^{t}
$$

where $\sigma_{D C}^{0}$ is the conductivity of the MWCNTS, $t$ is the critical exponent, $\phi$ is the carbon nanotube wt.\%, and is the electrical percolation threshold.

The $\phi_{c}$ values for EVA/MWCNT composite injectionmolded at 140 and $180^{\circ} \mathrm{C}$ were found to be 0.223 and 0.994 wt. $\%$, respectively. The low percolation threshold value for the composite injection-molded at low melt temperature is an indication of uniform dispersion of nanotubes during the melt processing [29].

Figure 7 shows the relative electrical resistance, $\left(R-R_{0}\right)$ / Rv, i.e. the ratio between the resistance change due to the applied strain and the initial electrical resistance, $R$, and the corresponding stress relaxation curve of EVA'/ MWCNT composite with $5 \mathrm{wt} \%$ for different applied strains at melt temperature of $180^{\circ} \mathrm{C}$.

The electrical resistance of EVA/MWCNT composite with 5 wt.\% increases with increasing tensile strain. At low strains ( $1 \%$ and below), there is only a slight increase in the electrical resistance, and the resistance returns to its initial value after the relaxation time, as shown in figure

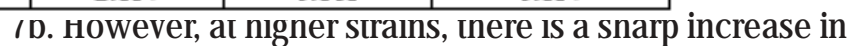
the electrical resistance with no return to its original value after the relaxation time.

Generally for a polymer/CNT composite to be electrically conductive, the nanotubes must either be in contact, or be sufficiently close to each other to enable conductance through tunnelling effect [30,31]. The increase on the electrical resistance with the applied strain can be attributed to changes in the carbon nanotube network configuration. Two competing mechanisms are developing during stretching of polymer/CNT composites: (i) deformation and breakdown of the conductive network and (ii) the formation of a new conductive network [30, 31]. When external loads are applied, the polymer chains and the conductive network are stretched and aligned in the direction of stretching; as a consequence, the average distance between the nanotubes increases, i.e., the tunnel junction gap increases [32] and the network breaks down, thus, the electrical resistance of the sample increases, as shown in figure 7.
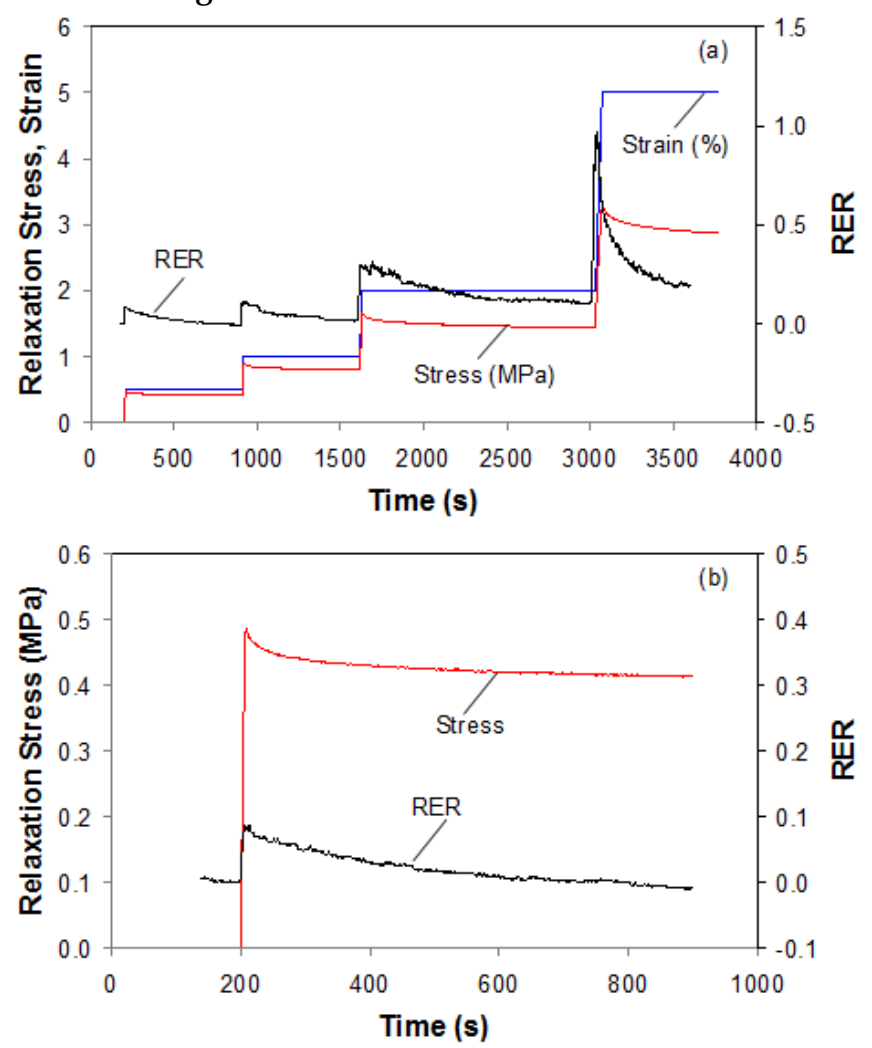

Fig. 7. Electrical and mechanical response of EVA composite with 5 wt.\% as a function of time and strain (Melt temperature of $180^{\circ} \mathrm{C}$ )

(a) and detail for $0.5 \%$ strain (b) 


\begin{tabular}{|c|c|c|c|c|c|}
\hline Melt temperature ('C) & $\begin{array}{c}\text { Initial strain level } \\
(\%)\end{array}$ & $\begin{array}{c}\text { MWCNTs } \\
\text { (wt.\%) }\end{array}$ & $R_{0}(\Omega)$ & Ros $(\Omega)$ & $\begin{array}{c}\text { Gauge } \\
\text { factor }\end{array}$ \\
\hline \multirow{5}{*}{140} & 0.5 & 3 & $1.09 \mathrm{E}+11$ & $1.27 \mathrm{E}+11$ & 15.63 \\
\cline { 2 - 6 } & 0.5 & 5 & $2.40 \mathrm{E}+07$ & $2.21 \mathrm{E}+07$ & 16.71 \\
\cline { 2 - 6 } & 1 & 3 & $1.33 \mathrm{E}+11$ & $1.42 \mathrm{E}+11$ & 27.17 \\
\cline { 2 - 6 } & 1 & 5 & $2.51 \mathrm{E}+07$ & $2.32 \mathrm{E}+07$ & 13.33 \\
\cline { 2 - 6 } & 2 & 3 & $1.59 \mathrm{E}+11$ & $1.62 \mathrm{E}+11$ & 26.64 \\
\cline { 2 - 6 } & 2 & 5 & $2.92 \mathrm{E}+07$ & $2.51 \mathrm{E}+07$ & 15.77 \\
\cline { 2 - 6 } & 5 & 3 & $2.02 \mathrm{E}+11$ & $2.18 \mathrm{E}+11$ & 19.04 \\
\hline \multirow{5}{*}{180} & 5 & 5 & $3.48 \mathrm{E}+07$ & $2.36 \mathrm{E}+07$ & 11.31 \\
\cline { 2 - 6 } & 0.5 & 3 & $1.17 \mathrm{E}+09$ & $1.02 \mathrm{E}+09$ & 56.66 \\
\cline { 2 - 6 } & 0.5 & 5 & $1.03 \mathrm{E}+05$ & $9.31 \mathrm{E}+04$ & 22.06 \\
\cline { 2 - 6 } & 1 & 3 & $1.42 \mathrm{E}+09$ & $1.47 \mathrm{E}+09$ & 82.44 \\
\cline { 2 - 6 } & 1 & 3 & $1.08 \mathrm{E}+05$ & $9.63 \mathrm{E}+04$ & 16.06 \\
\cline { 2 - 6 } & 2 & 3 & $1.34 \mathrm{E}+05$ & $1.10 \mathrm{E}+05$ & 24.08 \\
\cline { 2 - 6 } & 2 & 5 & $2.04 \mathrm{E}+05$ & $1.20 \mathrm{E}+05$ & 24.60 \\
\hline
\end{tabular}

Table 2

GAUGE FACTOR AS FUNCTION OF STRAIN FOR EVA FILLED WITH 3 AND 5 WT \% MWCNTS
For each applied strain value, $\Delta R / R_{0}$ is higher for samples with lower filler contents. For example, for $5 \%$ strain and melt temperature of $180^{\circ} \mathrm{C}, \Delta R / R_{0}$ of the sample with 5 wt.\% MW CNTs is about 1.23, while for the sample with 3 wt.\% MWCNTs is about 17.75 .

Figure 7 also shows that the relative electrical resistance has an exponential decay with time, which correlates with the stress relaxation. This can be attributed to the nanotube capacitive behavior [20,33].

To estimate the strain sensitivity of the EVA/MWCNT composites, the gauge factor was calculated [30-32, 34]:

$$
G F=\frac{\Delta R / R_{0}}{\varepsilon_{0}}
$$

where $\Delta R / R$ stands for the relative electrical resistance or sensitivity factor, and $\varepsilon_{0}$ is the initial applied strain.

Table 2 shows the gauge factor (GF) as a function of applied strain, nanotube wt.\%, and melt temperature. It should be noted that the EVA/MWCNT composite with 1 wt.\% of MWCNTs behaves like an insulator (the electrical resistance was greater than $10^{13} \mathrm{Ohm}$ ) and thus the gauge factor was not considered. As seen from table 2, the sensitivity of the EVA/MWCNT composite decreases with increasing nanotube loading. The highest sensitivity was achieved for the composite with 3 wt.\% of MWCNTs. Also, it can be seen that the melt temperature has an important effect on the gauge factor. The value of gauge factor for the composite injection-molded at $180^{\circ} \mathrm{C}$ is higher than that of the composite injection-molded at $140^{\circ} \mathrm{C}$.

\section{Conclusions}

In this paper, the time-dependence of the mechanical and electrical properties of EVA/MWCNT composite were investigated under tensile strains as a function MWCNT loading. The electrical resistance of the EVA/MWCNT composite was observed to increase with increasing strain, and exponentially decrease with relaxation time, indicating the capacitive behavior of MWCNTs. The EVA/MWCNT composite with $3 \mathrm{wt} . \%$ is the most sensitive one among the EVA/MWCNT composites. The electrical percolation of EVA/MWCNT composite was found to depend on the melt temperature. The electrical percolation threshold increased from $0.223 \mathrm{wt} . \%$ to $0.994 \mathrm{wt} . \%$ for the composite molded at $140^{\circ} \mathrm{C}$ and $180^{\circ} \mathrm{C}$ melt temperature, respectively. The maximum conductivity achieved was $7.35 \times 10^{-4} \mathrm{~S} /$ cm for 5 wt. \% EVA/MWCNT composite at $180^{\circ} \mathrm{C}$.
Acknowledgments: This work was partially supported by the POSCCE ProjectP0102421/5117/22.05.2014 (COD SMIS 50414).

\section{References}

1. GONZALEZ C., VILATELA J.J., MOLINA-ALDAREGUÍA J .M., LOPES C.S., LLORCA J., Prog. Mater. Sci., 89, 2017, p. 194;

2. YAZDI A., D'ANGELO L., OMER N., WINDIASTI G., LU X., XU J., Biosens. Bioelectron., 85, 2016, p. 536;

3. BANORIYA D., PUROHIT R., DWIVEDI R. K., Mater. Today-Proc., 4, 2017, p. 3534;

4. GAJENDIRAN M., CHOI J., KIM S.-J., KIM K., SHIN H., KOO H.- ., KIM K., J. Ind. Eng. Chem., 51, 2017, p. 12;

5. TANG Z., HE C., TIAN H., DING J., HSIAO B.S., CHU B., CHEN X., Prog. Polym. Sci., 60, 2016, p. 86;

6. CHEN H., GINZBURG V., YANG J., YANG Y., LIU W., HUANG Y., DU L., CHEN B., Prog. Polym. Sci., 59, 2016, p. 41;

7. YENGEJ EH S. I., KAZEMI S. A., ÖCHSNER A., Comp. Mater. Sci., 136, 2017, p. 85;

8. MASHHADZADEH A.H., FEREIDOON A., AHANGARI M.G., Appl. Surf. Sci., 420, 2017, p. 167;

9. KHATOON H., AHMAD S., J. Ind. Eng. Chem., 53, 2017, p. 1;

10. CHEN Y., YANG Q., HUANG Y., LIAO X., NIU Y., Polymer, 79, 2015, p. 159;

11. GONG S., ZHU Z.H., Polymer, 55, 2014, p. 4136;

12. VERTUCCIO L., VITTORIA V., GUADAGNO L., SANTIS F., Composites Part A, 71, 2015, p. 9;

13. CHEN J ., ZHANG Z.-X., HUANG W.-B., LI J.-L., YANG J .-H., WANG Y., ZHOU Z.-W., ZHANG J.-H., Mater. Design., 69, 2015, p. 105;

14. GONG S., ZHU Z.H., MEGUID S.A., Polymer, 55, 2014, p. 5488;

15. SANLI A., BENCHIROUF A., MÜLLER C., KANOUN O., Sensor. Actuator. A, 254, 2017, p. 61;

16. SOURI H., YU J ., JEON H., KIM J. W., YANG C.-M., YOU N.-H., YANG B.J ., Carbon, 120, 2017, p. 427;

17. REN X., CHAURASIA A. K., SEIDEL G. D., Int. J. Solids Struct., 96, 2016, p. 340;

18. PRAKASH N., SEIDEL G. D., Mater. Sci., 113, 2016, p. 154;

19. WANG F., LIU S., SHU L., TAO X.-M., Carbon, 121, 2017, p. 353;

20. ZHA J.-W., ZHANG B., LI R. K.Y., DANG Z.-M., Compos. Sci. Technol.,

123, 2016, p. 32;

21. CHAURASIA A.K., SEIDEL G.D., Eur. J Mech. A-Solid., 64, 2017, p. 112;

22. WANG F., LIU S., SHU L., TAO X.-M., Carbon, 121, 2017, p. 353;

23. SASMAL S., RAVIVARMAN N., SINDU B.S., VIGNESH K., Compos. Part. A-Appl. S., 100, 2017, p. 227;

24. PANOZZO F., ZAPPALORTO M., QUARESIMIN M., Composites Part B, 109, 2017, p. 53; 
25. LEE J.-Y., KUMAR V., TANG X.-W., LEE D.--., Compos. Sci. Technol., 142, 2017, p. 1;

26. NAM I.W., PARK S. M., LEE H.K., ZHENG L., Compos. Struct., 178, 2017, p. 1;

27. FLORY A., MCKENNA G.B., Mech. Time-Depend. Mater., 8, 2004, p. 17;

28. AGUILAR O., BAUTISTA-QUIJ ANO J.R., AVILeS F., Express Polym. Lett. 4, no. 5, 2010, p. 292;

29. LOGAKIS E., et al., Chem. Phys. Lett., 498, 2010, p. 125;
30. SAU K.P., CHAKI T.K., KHASTGIR D., Compos. Part A - Appl. Sci. Manuf., 29, no. 4, 1998, p. 363;

31. FLANDIN L., BRECHET Y., CAVAILLE J.-Y., Compos. Sci. Technol., 61, 2001, p. 895;

32. ZHANG R., BAXENDALE M., PEIJS T., Phys. Rev. B, 76, 2007, p. 195433;

33. CANEBA G., AXLAND J ., J. Miner. Mater. Character. Eng., 3, 2004, p. 73;

34. COSTA P., et al., J. Mater. Sci., 48, no. 3, 2013, p. 1172.

Manuscript received: 11.09 .2018 